\title{
Cholesterol-functionalized carvedilol-loaded PLGA nanoparticles: anti-inflammatory, antioxidant, and antitumor effects
}

\author{
Ana Luiza C. de S. L. Oliveira • Alaine M. dos Santos-Silva • Arnóbio A. da Silva-Júnior • \\ Vinícius B. Garcia • Aurigena A. de Araújo • Lioe-Fee de Geus-Oei • Alan B. Chan • Luis J. \\ Cruz • Raimundo F. de Araújo Júnior
}

Received: 2 January 2020 / Accepted: 30 March 2020 / Published online: 9 May 2020

(C) The Author(s) 2020

\begin{abstract}
The inflammation has been identified as factor of tumor progression, which has increased the interest and use of molecules with anti-inflammatory and antioxidant activities in the cancer treatment. In this

\footnotetext{
Highlights

- Cholesterol-functionalized carvedilol-loaded PLGA was obtained with satisfactory morphological characteristics such as small size and uniform surfaces.

- Nanoparticles exhibited physicochemical characteristics that provided a high drug loading efficiency of over $95 \%$.

- Improved antitumor activity was observed with NP CVDL and NP CVDL CHOL compared with free CVDL.

- NP CVDL CHOL improved antioxidant and anti-inflammatory effects of PLGA and free CVDL.
}

Electronic supplementary material The online version of this article (https://doi.org/10.1007/s11051-020-04832-8) contains supplementary material, which is available to authorized users.

A. L. C. de S. L. Oliveira • V. B. Garcia •

R. F. de Araújo Júnior

Postgraduate Program in Health Science, Federal University of Rio Grande do Norte (UFRN), Natal, RN, Brazil
A. L. C. de S. L. Oliveira • A. B. Chan · L. J. Cruz •
R. F. de Araújo Júnior ( $\square)$
Department of Radiology Translational Nanobiomaterials and Imaging, Leiden University Medical Center, 2333 ZA Leiden, Netherlands
e-mail: araujojr.morfologia@gmail.com

A. M. dos Santos-Silva · A. A. da Silva-Júnior Department of Pharmacy Laboratory of Pharmaceutical Technology and Biotechnology, Federal University of Rio Grande do Norte (UFRN), Natal, RN, Brazil study, the antioxidant, anti-inflammatory, and antitumor potentials of carvedilol was explored in a different approach. The cholesterol (CHO) was investigated as facilitated agent in the action of carvedilol-loaded

\author{
A. A. de Araújo \\ Department of Biophysics Postgraduate Programs in Public Health \\ and Pharmaceutical Science and Pharmacology, Federal \\ University of Rio Grande do Norte (UFRN), Natal, RN, Brazil \\ L.-F. de Geus-Oei \\ Department of Radiology Nuclear Medicine, Leiden University \\ Medical Center, Leiden, Netherlands \\ A. B. Chan \\ Percuros B.V., Leiden, Netherlands \\ R. F. de Araújo Júnior \\ Department of Morphology Postgraduate Program in Functional \\ and Structural Biology, Federal University of Rio Grande do Norte \\ (UFRN), Natal, RN, Brazil
}


nanoparticles. Different formulations exhibited spherical and stable nanoparticle with mean diameter size < $250 \mathrm{~nm}$. The cholesterol changed the copolymer-drug interactions and the encapsulation efficiency. The in vitro cancer study was performed using murine colorectal cancer cell line (CT-26) to observe the cell viability and apoptosis on MTS assay and flow cytometry, respectively. The experiments have demonstrated that cholesterol improved the performance of drug-loaded nanoparticles, which was much better than free drug. The in vivo inflammation peritonitis model revealed that carvedilol-loaded nanoparticles increased the level of glutathione and leukocyte migration mainly when the functionalized drug-loaded nanoparticles were tested, in a lower dose than the free drug. As hypothesized, the experimental data suggest that cholesterolfunctionalized carvedilol-loaded PLGA nanoparticles can be a novel and promising approach in the inflammation-induced cancer therapy since showed anti-inflammatory, antioxidant, and antitumor effects.

Keywords Cancer - Inflammation - Oxidative stress · Colloidal nanocarriers $\cdot$ Functionalized nanoparticles · Drug delivery systems $\cdot$ Nanomedicine

\section{Introduction}

Inflammation and cancer are two interrelated pathological processes, it is well known that inflammation plays a role in tumor progression and that anti-inflammatory therapy can be an ally in the treatment of tumor development (Coussens and Werb 2002; Ghuman et al. 2017). Colorectal cancer (CRC) is an example of cancer whose risk factor is inflammatory bowel disease, which participates in the process of tumor progression (West et al. 2015). The inflammation-mediated CRC tumorigenesis mechanism is correlated to an action of proinflammatory cytokines and reactive oxygen species, activating transcription factors, such as NF-kB and STAT3, involved in tumor proliferation pathways and apoptosis inhibition (Elinav et al. 2013; Ghuman et al. 2017; Taniguchi and Karin 2018). The development of new anticancer approach that can take cancer cells to apoptosis, without the harmful side effects caused by conventional cancer therapies, is one of exciting challenges of modern medicine. Even though carvedilol (CVDL) is classified as a non-selective beta-adrenergic receptor blocker $(\beta 1, \beta 2)$, which has been used for treating hypertension, angina pectoris, small myocardial infarction, tachyarrhythmia, and congestive heart failure (Balaha et al. 2016), studies have shown that it has also antioxidant, anti-inflammatory, pro-apoptotic, antifibrotic, antiproliferative, and anticancer properties (Araújo Júnior et al. 2016; Areti et al. 2017; De Araujo et al. 2018; Félix et al. 2017; Yao et al. 2016).

As one alternative to the smart use of drug efficiency, nanoparticles can be used as drug delivery systems (DDSs) enable to increase the solubility of hydrophobic drugs, the distribution of higher drug concentrations to target areas due to an Enhanced Permeation and Retention (EPR) effect and provides the sustained and controlled release of encapsulated drugs. This can lead to lower doses of drugs, thus reducing side effects (Goyal et al. 2016; Lee et al. 2015). Different types of nanoparticles (NPs) can be formulated such as liposomes, dendrimers, carbon nanotubes, inorganic, and NPs based on proteins and polymers, each with their own properties. Poly (D, L-lactide-co-glycolide) (PLGA) is a type of polymer approved by the European Medicines Agency (EMA) and Food and Drug Administration (FDA), applied in the development of DDSs (Masloub et al. 2016; Ramezanpour et al. 2016). In this way, nanoparticles can be used for targeted site-specific delivery, which facilitates their internalization into cancer cells and for co-delivering multiple factors to the same cell/tissue site (Bahrami et al. 2017; Kapadia et al. 2015; Milling et al. 2017). Several targeting ligands are used for drug delivery such as antibodies, peptides, folate, glycoproteins, and cholesterol (CHOL) (Bahrami et al. 2017; Varan et al. 2016). Cholesterol is an important structural component in cells which is involved in many biological processes such as endocytosis of materials and proliferation of cancer and metastasis. Cancer cells have rapid metabolism, requiring more nutrients. Therefore, CHOL is required for synthesizing new membranes (Lee et al. 2016; Varan et al. 2016). In this context, the large number of reports on PLGA NPs used as drug delivery systems for cancer treatment highlights the potential of PLGA NPs as carriers of cancer therapy drugs.

Therefore, the aim of the present study was to verify the in vitro and in vivo performance of carvedilolloaded polymeric nanoparticles and the effects of modifying particle surfaces induced by CHOL to improve cell uptake of carvedilol as a chemotherapy agent. The interactions among the involved compounds and 
physicochemical properties of distinct formulations were carefully monitored using an analytical approach. Enhancing the biological efficacy in the inflammatory process and against tumor cells by carvedilol-loaded polymeric induced by $\mathrm{CHOL}$ is an interesting and relevant achievement which is not yet reported in literature.

\section{Experimental section}

\section{Reagents}

For formulation of the nanoparticles, the following compounds were used: copolymer PLGA (poly (lactic-coglycolic acid) (Sigma-Aldrich, Saint Louis, MO, EUA), CVDL (Espaço Pharma®, RN, Brazil), CHOL (92.5\%, Vetec ${ }^{\circledR}$, Sigma-Aldrich, Saint Louis, MO, USA), and poly vinyl alcohol (PVA) with viscosimetric molecular mass of $4.7 \times 10^{4} \mathrm{~g} / \mathrm{mol}$ Vetec (São Paulo, Brazil). The organic solvents: acetone (ACE) and dichloromethane (DCM) (were purchased from Labsynth ${ }^{\circledR}$ (São Paulo, Brazil). Dimethyl sulfoxide (DMSO) was purchased from Sigma-Aldrich (CA, USA). For in vitro assays, the following reagents were used: CellTiter $96 \mathrm{AQ}_{\text {ueous }}$ One Solution (MTS) solution (Promega Corporation, Madison, WI), DAPI (Life Technologies, the Netherlands), and Annexin V-FITC (BD Pharmingen, CA, USA). Purified water $(1.3 \mu \mathrm{S})$ was obtained from reverse osmosis purification equipment model OS50 LX (Gehaka, SP, Brazil). All other chemicals and reagents were of analytical grade.

\section{Preparation and characterization of nanoparticles}

Nanoparticles were prepared by the emulsificationsolvent evaporation method (Pooja et al. 2016; Zhu et al. 2012), following a previously standardized nanoparticulate system (dos Santos-Silva et al. 2017). First, the organic phase $(\mathrm{OP})(6 \mathrm{~mL})$ containing the PLGA was injected into the aqueous phase (AP) (14 $\mathrm{mL}$ containing the solution of PVA surfactant in water) under magnetic stirring at $720 \mathrm{rpm}$ at $25^{\circ} \mathrm{C}$. The AP was previously filtered using $0.45-\mu \mathrm{m}$ membranes. Emulsification was followed in Ultra-turrax equipment (IKA Labortechnik, Germany) at $25^{\circ} \mathrm{C}$ for $18 \mathrm{~min}$ and evaporation of the solvent occurred under magnetic stirring at $720 \mathrm{rpm}$ overnight. Samples were placed in hermetically sealed glass flasks and stored at $5{ }^{\circ} \mathrm{C}$ in a freezer.
Preparation of surface-modified nanoparticles

Surface-modified and CHOL NPs were prepared as in the "Preparation and characterization of nanoparticles" section. The CHOL was inserted in a ratio of 1:10 relative to the CVDL in the polymeric OP following the same evaluation procedure in which nanoparticles were not functionalized.

Preparation of drug-loaded nanoparticles

The PLGA $1.0 \% \mathrm{w} / \mathrm{v}$ solution in the OP composed by DCM:ACE at 25:75 v/v was injected in the aqueous solution of PVA $0.5 \% \mathrm{w} / \mathrm{v}$, using a burette in a flow of $1.0 \mathrm{~mL} / \mathrm{min}$ under magnetic stirring at $720 \mathrm{rpm}$. Emulsification followed a stirring speed of 20,000 rpm for $18 \mathrm{~min}$ (dos Santos-Silva et al. 2017). Different concentrations of drug were dissolved with the polymer in the organic solvent to supply drug/copolymer ratios of $1: 2.5,1: 5,1: 10$, and 1:20 relative to the PLGA.

Particle size and zeta potential measurements

Mean particle size and polydispersity index (PdI) were assessed by using the dynamic light scattered (DLS) by the particle size analyzer (Zetasizer Nano ZS, Malvern instruments, Malvern, UK) at 659-nm wavelength, temperature of $25 \pm 2{ }^{\circ} \mathrm{C}$, and an angle of $173^{\circ}$ to the incident beam. Zeta potential measurements were performed in the same equipment using Zeta Potential Analyzer software by electrophoretic mobility. The measurements average of ten determinations for each sample diluted at 1:100 (v/v) with purified water were carried out in triplicate and data expressed as mean \pm standard deviation (SD).

Atomic force microscopy

The topographic image and the surface of the particles in atomic resolution of drug-free and CVDL-loaded nanoparticles were observed by using atomic force microscopy (AFM) images. The dispersions were freshly diluted in a ratio of 1:25 (v/v) using purified water and placed on a glass coverslips, dried under a desiccator for $24 \mathrm{~h}$, and then analyzed in an AFM SPM-9700 Shimadzu microscope (Tokyo, Japan) at room temperature with a non-contact cantilever and 1-Hz scanning (Dos Santos-Silva et al. 2019). 
Physicochemical stability

The drug-free nanoparticles and CVDL-loaded nanoparticles were hermetically stored for 7 weeks in closed flasks at $5{ }^{\circ} \mathrm{C}$. The samples were collected at intervals of 7 days and had their size and zeta potential evaluates. The measurements were performed using the parameters described in the "Particle size and zeta potential measurements" section.

Attenuated total reflectance Fourier transform infrared spectroscopy

The drug-copolymer interactions in the nanoparticles without carvedilol (NP), carvedilol-loaded (NP CVDL), and carvedilol-loaded functionalized with cholesterol (NP CVDL CHOL) were assessed by attenuated total reflectance Fourier transform infrared spectroscopy (ATR-FTIR). The colloidal dispersion of nanoparticles was concentrated using the vacuum concentrator (Labconco Centrivap) for 7-8 h. The spectra were recorded with a resolution of $4 \mathrm{~cm}^{-1}$ between 4000 and $500 \mathrm{~cm}^{-1}$ at $20 \mathrm{scans}$, for pure compounds (PLGA, CVDL, CHOL), and polymeric nanoparticles in a SHIMADZU IR Prestige 21 FTIR-ATR spectrophotometer (Tokyo, Japan).

\section{Drug loading efficiency}

The samples were centrifuged for during $60 \mathrm{~min}$ at $4{ }^{\circ} \mathrm{C}$ (Eppendorf ${ }^{\circledR}$ Microcentrifuge 5404R) at $16.0 \times \mathrm{g}$ using the ultra-centrifugal filter (Sartorius ${ }^{\circledR}$, Vivaspin 2, Ultra-15 MWCO $10 \mathrm{kDa}$ ). The drug in the supernatant was analyzed at $241 \mathrm{~nm}$, which was the maximum absorption wavelength for the CVDL using the previously validated UV-Vis spectrophotometry. All analyses were performed in triplicate, and the data expressed as mean \pm standard deviation (SD). The encapsulation efficiency (EE\%) was calculated using Eq. (1), as described by Dos Santos Silva (dos Santos Silva et al. 2019).

$\mathrm{EE}(\%)=($ total drug-drug in the supernatant $) /$ total drug $\times 100$
In vitro drug release performance

In vitro drug release analyzed was made using static Franz vertical diffusion cells (Crown Scientific, Sommerville, USA) thermostatted at $37 \pm 0.5^{\circ} \mathrm{C}$. First, $3.0 \mathrm{~mL}$ of distinct nanoparticles (NP CVDL, NP CVDL CHOL) and CVDL solution were applied and hermetically sealed in the donor compartment and separated from the receptor compartment by a synthetic cellulose acetate $0.45-\mu \mathrm{m}$ filter, previously hydrated for $24 \mathrm{~h}$ in phosphate buffer solution (PBS). The receptor compartment was filled with $11.0 \mathrm{~mL}$ of PBS adjusted for $\mathrm{pH} 7.4$, which remained under magnetic stirring at $360 \mathrm{rpm}$ during the entire experiment. Aliquots of $1.0 \mathrm{~mL}$ were withdrawals at seven specific intervals (30 to $600 \mathrm{~min}$ ) and analyzed by previously validated UV spectrophotometry at $241 \mathrm{~nm}$. The same volume of freshly buffered solution replaced the medium to maintain the sink conditions ( $\mathrm{Ng}$ et al. 2010). The release data were then analyzed using linear regression according to mathematical models to determine the release mechanism of carvedilol from its NPs. The correlation coefficient $[R]$ was determined in each case, and the orders of release were accordingly determined.

In vitro anti-CRC studies

\section{Cell line and cultivation}

The murine CRC cell line CT-26 (CT-26.WT, ATCC® CRL-2638 ${ }^{\mathrm{TM}}$; ATCC, Manassas, VA, USA) was cultivated in Dulbecco's Modified Eagle Medium (DMEM) (Thermo Fisher Scientific, MA, USA) supplemented with $10 \%(\mathrm{v} / \mathrm{v})$ fetal bovine serum (FBS) and $1 \%$ antibiotics (penicillin/streptomycin) in $37{ }^{\circ} \mathrm{C}$ incubator with atmosphere of $5 \% \mathrm{CO}_{2}$ and was passaged twice a week by removing the adherent cells with trypsin/EDTA in buffered saline.

\section{Cell viability assay (MTS)}

MTS assay for the PLGA nanoparticles conjugated with CVDL was determined based on the reduction of the MTS tetrazolium compound to formazan product by living cells in culture. CT-26 cell lines were plated in 96-well plates with a density of $3 \times 10^{3}$ cells/well. Applications of free CVDL and drug-loaded nanoparticles at concentrations of $0.3 \mu \mathrm{g} / \mathrm{mL}, 0.78 \mu \mathrm{g} / \mathrm{mL}, 1.56 \mu \mathrm{g} /$ $\mathrm{mL}, 3.12 \mu \mathrm{g} / \mathrm{mL}$, and $6.2 \mu \mathrm{g} / \mathrm{mL}$ were then performed 
after $24 \mathrm{~h}$ under culture conditions (De Araujo et al. 2018). MTS solution was added to medium without cells as a blank control. Treatments were evaluated at $24 \mathrm{~h}$ and $48 \mathrm{~h}$ by the addition of $20 \mu \mathrm{L} /$ well of MTS solution after replacing the treatment medium with a new one. After incubation for $2 \mathrm{~h}$, the fluorescence was measured using a microplate reader (VersaMax Molecular Devices, Sunnyvale, CA) with absorbance being measured at $490 \mathrm{~nm}$. All data points represent triplicates for each treatment.

\section{Evaluation of in vitro cell death}

The effect of free CVDL and nanoconjugates on CT-26 cells was determined by double-labeled flow cytometry with Annexin V-FITC and DAPI, which enables identifying apoptotic and necrotic cells through loss of membrane integrity. Cell lines were arranged in 24-well plates with a density of $1 \times 10^{4}$ cells/well, at a total volume of $500 \mu \mathrm{L}$. After $24 \mathrm{~h}$ of incubation under culture conditions, the cells were treated with the samples at doses of $0.3 \mu \mathrm{g} / \mathrm{mL}, 0.78 \mu \mathrm{g} / \mathrm{mL}$, and $1.56 \mu \mathrm{g} /$ $\mathrm{mL}$ at $24 \mathrm{~h}$ and $48 \mathrm{~h}$. The cells were obtained after each period by collecting the supernatant from the wells, washing with PBS, trypsinization, and centrifugation at $3200 \mathrm{rpm}$ at $4{ }^{\circ} \mathrm{C}$ for $5 \mathrm{~min}$. Finally, they were labeled with Annexin V-FITC and DAPI, and analyzed with BD LSR-II (BD Biosciences, CA, USA) and FlowJo software version 7.6.5 (Tree Star Inc., CA, USA).

In vivo inflammation and oxidative stress studies

\section{Animal preparation}

Female Swiss mice at 9 weeks old $(40 \pm 2.0 \mathrm{~g})$ were obtained from the UFRN Vivarium Center of Biosciences. Animals were maintained under standard 12-h light/dark cycle, $22 \pm 0.1{ }^{\circ} \mathrm{C}$, and $50-55 \%$ humidity with ad libitum access for food and water. The mice were subjected to 12-h fasting prior to the experiments. Euthanasia was performed with a subcutaneous administration of $90 \mathrm{mg} / \mathrm{kg}$ sodium thiopental $(0.5 \%$, Tiopentax, Cristália, São Paulo, Brazil). This study was carried out in strict accordance with the recommendations in the Guide for the Care and Use of Laboratory Animals of the National Institutes of Health. The protocol was approved by the Committee on the Ethics of Animal Experiments of the UFRN (CEUA, Permit Number: 001/2015).
The carrageenan-induced peritonitis model

Mice were randomly distributed into twelve groups ( $n=$ 5/group). The mice were orally pre-treated with a vehicle $(0.9 \%$ saline solution)/carrageenan group, drug-free nanoparticle (NP) (1 mL of a $1 \mathrm{mg} / \mathrm{mL}$ preparation), free CVDL ( $3 \mathrm{mg} / \mathrm{kg}$ and $0.3 \mathrm{mg} / \mathrm{kg}$ ), NP CVDL ( $0.3 \mathrm{mg} / \mathrm{kg}$, $0.1 \mathrm{mg} / \mathrm{kg}$ and $0.05 \mathrm{mg} / \mathrm{kg}$ ), NP CVDL CHOL $(0.3 \mathrm{mg} / \mathrm{kg}, 0.1 \mathrm{mg} / \mathrm{kg}$, and $0.05 \mathrm{mg} / \mathrm{kg})$, or Diclofenac $(10 \mathrm{mg} / \mathrm{kg})$ in order to evaluate the effect of PLGA, the association of PLGA with CVDL or CVDL and CHOL combined on leukocyte recruitment into the peritoneal cavity. After $30 \mathrm{~min}, 0.25 \mathrm{~mL}$ of a $1 \%$ carrageenan solution (Sigma-Aldrich, São Paulo, Brazil) was intraperitoneally (i.p.) injected. The sham group received a vehicle $(1 \mathrm{~mL}$ water $/ 10 \mathrm{~g})$ and a $0.9 \%$ sterile saline solution intraperitoneal injection $(0.1 \mathrm{~mL} / 10 \mathrm{~g})$ (Ribeiro et al. 1991). Then, the mice were euthanized $4 \mathrm{~h}$ later with an overdose of $90 \mathrm{mg} / \mathrm{kg}$ sodium thiopental. Three milliliters of saline solution was then injected into each abdominal cavity and peritoneal fluid was collected and diluted (1:20) in Turk's solution. A total leukocyte count was performed for each sample with a Neubauer counting chamber. The samples were stored at $-80^{\circ} \mathrm{C}$ for subsequent analyses of malondialdehyde (MDA) and total glutathione (GSH) levels.

Glutathione levels

GSH levels assessment was performed according to the method described by Anderson (Anderson 1985). Briefly, $100 \mu \mathrm{L}$ of each inflammatory lavage was diluted in a $5 \%$ trichloroacetic acid (TCA)/distilled water solution and centrifuged at $10,000 \mathrm{rpm}$ for $15 \mathrm{~min}$ at $4{ }^{\circ} \mathrm{C}$. Each standard dilution $(20 \mu \mathrm{L})$, TCA solution $(20 \mu \mathrm{L}$, Vetec, São Paulo, Brazil) for the blank, and each sample supernatant $(20 \mu \mathrm{L})$ were added to 96 -well plates in duplicate. In addition, $15 \mu \mathrm{L}$ PBS-EDTA, $20 \mu \mathrm{L}$ dithiobisnitrobenzoic acid (DTNB) solution, and $140 \mu \mathrm{L}$ NADPH were added to each well. After an incubation step at $30^{\circ} \mathrm{C}$ for $5 \mathrm{~min}, 15 \mu \mathrm{L}$ of an enzyme solution and GSH reductase (Sigma-Aldrich, São Paulo, Brazil) were added to each well. Absorbance values at $412 \mathrm{~nm}$ were recorded by spectrocopical UV/VIS analysis (Biotek, São Paulo, Brazil) for $3 \mathrm{~min}$. Total GSH content was calculated based on interpolations from a standard curve that was generated with purified glutathione ( $\gamma$-L-Glutamyl-L-cysteinyl-glycine, GSH, Sigma-Aldrich, São Paulo, Brazil, G4251). The results of 
this assay are expressed in nanomoles per microliter of sample.

\section{Malonyldialdehyde assay}

Malonyldialdehyde (MDA) is a product of lipid peroxidation. To quantify the increase in free radicals in liver sample, MDA content was measured via the assay described by Esterbauer and Cheeseman (Esterbauer and Cheeseman 1990). First, each sample $(50 \mu \mathrm{l})$ was diluted in Tris $\mathrm{HCl}$ buffer $(250 \mu \mathrm{L}, 20 \mathrm{mM})$ (Trizma hydrochloride, Sigma Aldrich, São Paulo, Brazil) in distilled water $(20 \mathrm{mM}, \mathrm{pH}$ 7.4). Peritoneal fluid samples were homogenized and centrifuged $(10.000 \mathrm{rpm}$ for $10 \mathrm{~min}$ at $4{ }^{\circ} \mathrm{C}$ ), then $750 \mu \mathrm{L}$ of $10.3 \mathrm{mM} \mathrm{1-methyl-2-}$ phenylindole and $225 \mu \mathrm{L} \mathrm{HCl}(37 \%)$ were added to each sample. Samples were incubated in a water bath for $40 \mathrm{~min}$ at $45^{\circ} \mathrm{C}$, and centrifuged at $10.000 \mathrm{rpm}$ for $5 \mathrm{~min}$ at $4{ }^{\circ} \mathrm{C}$. Absorbance values at $586 \mathrm{~nm}$ were recorded with a spectroscopic UV/VIS analysis (Biotek, São Paulo, Brazil) and the results were interpolated from a standard curve that was established with 1,1,3,3tetraethoxypropane. The results from this assay are expressed as nanomoles per microliter of sample.

\section{Statistical analysis}

All analyses of nanoparticles were performed in triplicate and data expressed as mean \pm standard deviation (SD). The significant differences between the groups were calculated using the analysis of variance (ANOVA) and the Bonferroni's test as indicated, in which $p<0.05$ was considered statistically significant.

\section{Results}

Preparation and characterization of nanoparticles

Figure $1 \mathrm{a}$ shows the results of the nanoparticles prepared for emulsification-solvent evaporation method, using a concentration of PLGA $1.0 \%$ and PVA $0.5 \%$, with solvent ratio DCM: ACE 25:75 (v/v). Nanoparticles were prepared as CVDL-free nanoparticles (NP) and nanoparticles in different CVDL: copolymer ratios (NP CVDL 1:10, NP CVDL 1:5, and NP CVDL 1:2.5) (Fig. 1a). The nanoparticles showed the formation of the smallest particles $(209.1 \pm 2.03 \mathrm{~nm}$ at $373.4 \pm 19.3 \mathrm{~nm}$, desirable values of zeta potential $(-2.0 \pm 4.2 \mathrm{mV}$ at $5.7 \pm 1.3 \mathrm{mV})$ and polydispersity index $(0.137 \pm 0.01$ at $0.248 \pm 0.07)$. The highest drug loading efficiency $(95.06 \pm 0.4 \%)$ was observed for the nanoparticle containing CVDL:PLGA weight-ratio of $1: 10$, which corresponds to a final drug concentration in the nanoparticle of $1 \mathrm{mg} / \mathrm{mL}$. CHOL was inserted as functionalizing substance in this best drug:polymer ratio. The results obtained are shown in Table 1. A slight increase in particle size was observed when NP CVDL (227.3 \pm $9.07 \mathrm{~nm}$ ) and NP CVDL CHOL were compared (234.7 $\pm 18.7 \mathrm{~nm}$ ), and a consequent decrease in encapsulation efficiency $(95.06 \pm 0.4$ at $37.45 \pm 1.8)$

The AFM images (Fig. 1) assessed topography aspects such as the shape and the surface of particles. The 2D images were obtained for the nanoparticles without drug (Fig. 1(B1)), the nanoparticle with drug in the proportion of 1:10 (Fig. 1(B2)), and the nanoparticle with drug and $\mathrm{CHOL}$ were observed in $2 \mathrm{D}$ and $3 \mathrm{D}$ images, respectively (Fig. 1(B3, B4)). Both drug-free, drug-containing nanoparticles and drug-containing functionalized nanoparticles showed slightly spherical shapes with smooth and uniform surfaces.

Figure 2 a shows the comparisons of the ATR-FTIR spectrum bands for the pure compounds (CVDL, PLGA, and CHOL), for the drug-free nanoparticle (NP), for the nanoparticle with the drug (NP CVDL), and for the functionalized nanoparticle with the drug (NP CVDL CHOL). The result was presented mainly comparing the bands of the nanoparticle with drug with the bands of the pure compounds, still highlighting the behavior of the functionalized nanoparticles. Carvedilol showed N-H peak of aromatic amines at $3400 \mathrm{~cm}^{-1}$ and weak peak of angular deformation $\mathrm{N}-\mathrm{H}$ bonds at $1.580 \mathrm{~cm}^{-1}$ used to characterize secondary amines of the drug structure. It is possible to observe peaks of aliphatic $\mathrm{C}-\mathrm{H}$ between 2960 and $2850 \mathrm{~cm}^{-1}$, while bands of $\mathrm{C}=\mathrm{C}$ vibrations of aromatic nuclei are observed between 1600 and $1450 \mathrm{~cm}^{-1}$. The isolated PLGA showed characteristic absorption peaks with significant $\mathrm{N}-\mathrm{C}$ stretch peaks close to $1300 \mathrm{~cm}^{-1}$ and $\mathrm{C}=\mathrm{O}$ monomeric peaks of the carboxylic acid at about $1750 \mathrm{~cm}^{-1}$. The CHOL spectrum alone shows a broad band between 3250 and $3500 \mathrm{~cm}^{-1}$ due to the elongation vibration of the $\mathrm{O}-\mathrm{H}$ bond. The NP, NP CVDL, and NP CVDL CHOL specters were also compared (Fig.2a). In the spectrum of NPs, the peaks in the region of $1750 \mathrm{~cm}^{-1}, 1180 \mathrm{~cm}^{-1}$, and $1050 \mathrm{~cm}^{-1}$ stand out, respectively, corresponding to monomeric peaks of the 


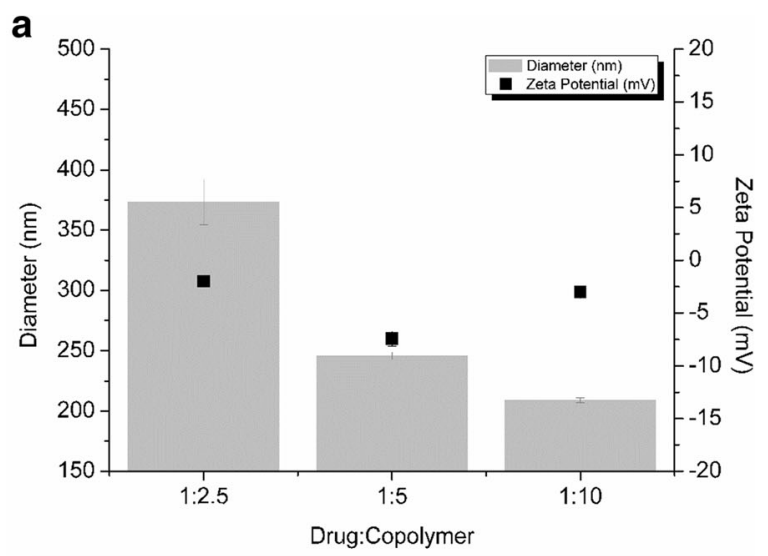

b
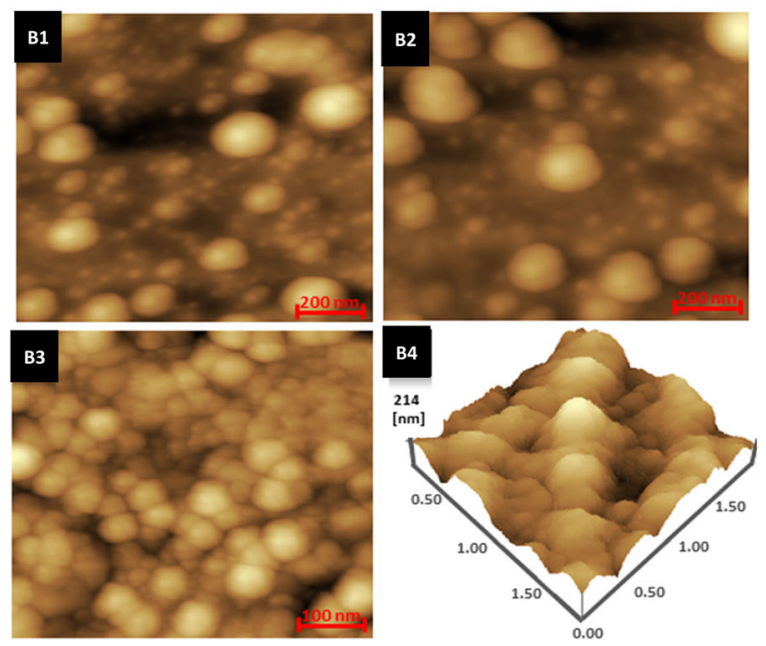

Fig. 1 a Mean diameter and zeta potential as a function of concentration of the drug: PLGA copolymer. b AFM images of (B1) NP, (B2) NP CVDL, and (B3, B4) NP CHOL in 2D and 3D respectively

$\mathrm{C}=\mathrm{O}$, aliphatic peaks of the $\mathrm{C}-\mathrm{N}$ and $\mathrm{C}-\mathrm{O}$ peaks present in the aromatic group

Figure $2 \mathrm{~b}$ shows the release profile of CVDL and distinct formulations of the CVDL-loaded polymeric nanoparticles. The successful drug efficiency in the PLGA nanoparticles, previously demonstrated, assured the desired slow release rate for all formulations (Danhier et al. 2012; Hans and Lowman 2002; Lee et al. 2016). We further subjected the data to four different diffusion kinetic linear models, which include the first-order model, the Bhaskar model, the modified Freundlich model, and parabolic model [Araújo et al.]. The calculated parameters are shown in Table 2. In these equations, $M t / M \infty, t$, and $k$ correspond to the fractional drug release, release time and release rate constant, respectively. The $a$ is a constant whose chemical significance is not clearly resolved. The Bhaskar model showed the best correlation $(R=0.96 \pm 0.02$ to $0.97 \pm$ 0.02) for all formulations

The physicochemical stability test was performed to monitor the time-dependent changes in the NP, NP CVDL, and NP CVDL CHOL. The analysis intervals were 7 days (for 7 weeks). The performed tests were of particle size, polydispersity index, and zeta potential, as shown in Fig. 2c. Analyses from the first to the seventh week particle size for NP values ranged from $\sim 209$ to $213 \mathrm{~nm}$, and the PDI values ranged from $\sim 0.130$ to $0.165 \mathrm{~nm}$. The particle size for NP CVDL ranged from $\sim 227$ to $233 \mathrm{~nm}$ and the PDI values ranged from 0.223 to $0.229 \mathrm{~nm}$. The particle size for NP CVDL CHOL ranged from $\sim 234$ to $239 \mathrm{~nm}$ and the PDI values ranged from $\sim 0.081$ to $0.109 \mathrm{~nm}$. The zeta potential for all formulations ranged from $\sim-2$ to $-4 \mathrm{mV}$.

\section{In vitro anti-CRC studies}

The results obtained with MTS assay showed that after the time points treatment with free CVDL, NP, NP CVDL, and NP CVDL CHOL, the proliferation of the CRC cell line CT-26 was compared with the negative control. The NP treatment did not alter the cell line viability after $24 \mathrm{~h}$ and $48 \mathrm{~h}$ (Fig. 3a, b).

After $24 \mathrm{~h}$ of treatment, CVDL $(3.12 \mu \mathrm{g} / \mathrm{mL}$ and $6.25 \mu \mathrm{g} / \mathrm{mL}$ ) decreased the proliferation rate of CT-26, $p<0.01$ and $p<0.05$, respectively. NP CVDL CHOL also showed the same result in a lower dose $(0.78 \mu \mathrm{g} /$ $\mathrm{mL}, p<0.01$ ) (Fig. 3a). There was a decrease in the CT26 cell viability when NP CVDL was used in $0.35 \mu \mathrm{g} /$ $\mathrm{mL}(p<0.05), 1.56 \mu \mathrm{g} / \mathrm{mL},(p<0.0001), 3.12 \mu \mathrm{g} / \mathrm{mL}$ $(p<0.0001)$, and $6.25 \mu \mathrm{g} / \mathrm{mL}(p<0.0001)$ doses for 48 h. Free CVDL and NP CVDL CHOL presented similar activity after $48 \mathrm{~h}$ by reducing the proliferation of the tumor line with the same statistical value $(p<0.0001)$ at $0.78 \mu \mathrm{g} / \mathrm{mL}, 1.56 \mu \mathrm{g} / \mathrm{mL}, 3.12 \mu \mathrm{g} / \mathrm{mL}$, and $6.25 \mu \mathrm{g} / \mathrm{mL}$ concentrations (Fig. 3b).

According to the flow cytometry, Fig. 2 shows the percentage of cell death of the treatments with free CVDL, NP CVDL, and NP CVDL CHOL $(0.35 \mu \mathrm{g} /$ $\mathrm{mL}, 0.78 \mu \mathrm{g} / \mathrm{mL}, 1.56 \mu \mathrm{g} / \mathrm{mL}$ ) for 24 -h or 48 -h treatment when compared with the negative control. The percentage is the sum of Annexin V-FITC-positive/ DAPI-negative and Annexin V-FITC-positive/DAPIpositive cells. Dot plots of flow cytometry for 24 (A) hours and $48 \mathrm{~h}(\mathrm{~B})$ are shown in supplementary material. 

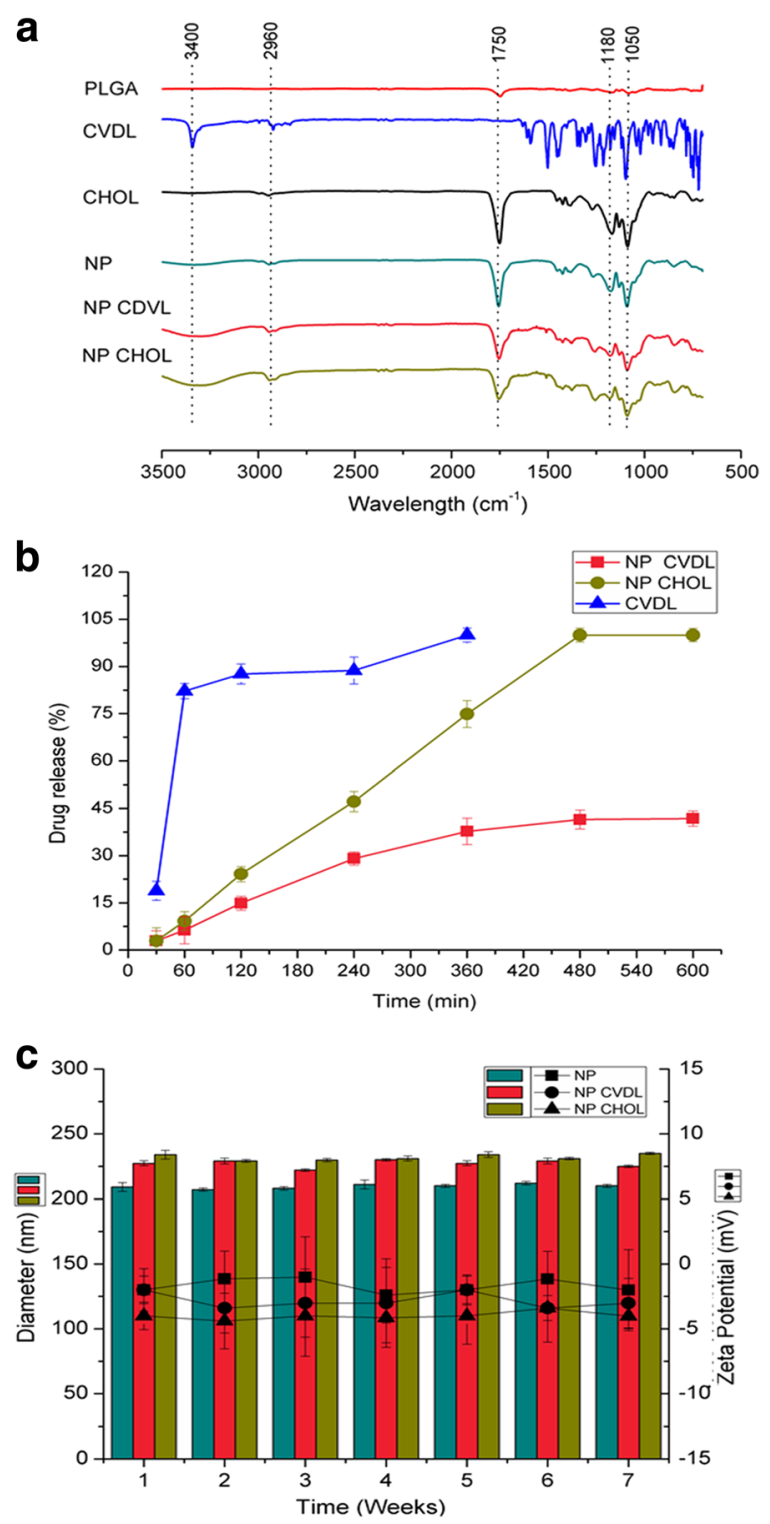

Fig. 2 a ATR-FTIR spectra for pure compounds (CVDL, PLGA, and $\mathrm{CHOL}$ ) and nanoparticles (NP, NP CVDL, and NP CHOL). b Experimental in vitro release profile from CVDL solution and nanoparticles CVDL content (NP CDVL and NP CHOL). c Physicochemical stability is expressed in mean diameter and zeta potential as a function of storage time for the drug-free nanoparticles (NP) and drug-loaded nanoparticles (NP CVDL and NP $\mathrm{CHOL})$. Note: The data are expressed as mean \pm standard deviation (SD) $(n=3)$

All the samples presented antitumor activity in both time points. After $24 \mathrm{~h}$, the treatment at $0.35 \mu \mathrm{g} / \mathrm{mL}$ concentration increased the total death with CVDL $(p<0.001)$, NP CVDL $(p<0.0001)$, and NP CVDL CHOL $(p<0.0001)$. The NP CVDL also increased the total death at $0.78 \mu \mathrm{g} / \mathrm{mL}, p<0.05$ (Fig. 3c). When treatment time was increased to $48 \mathrm{~h}$, the quantity of death also increased, in which CVDL $0.78 \mu \mathrm{g} / \mathrm{mL}$ induced cell death $(p<0.0001)$, as well as NP CDVL and NP CVDL CHOL for the three doses used $(p<0.0001)$ (Fig. 3d).

When free CVDL with NP CVDL and NP CVDL CHOL at the same concentration is compared, it is observed that there is a difference between antitumor activity of the nanoconjugates and the free CVDL. An increase in this activity for the three evaluated concentrations was observed at $48 \mathrm{~h}$ (Fig. 3e). The $p$ values for this comparison are as follows: (i) for $0.35 \mu \mathrm{g} / \mathrm{mL}$, CVDL vs NP CVDL $(p<0.0001)$ and CVDL vs NP CVDL CHOL $(p<0.0001)$; (ii) for $0.78 \mu \mathrm{g} / \mathrm{mL}$, CVDL vs NP CVDL $(p<0.0001)$ and CVDL vs NP CVDL CHOL $(p<0.0001)$; and (iii) for $1.56 \mu \mathrm{g} / \mathrm{mL}$, CVDL vs NP CVDL $(p<0.01)$ and CVDL vs NP CVDL CHOL $(p<0.0001)$ (Fig. 3e).

In vivo inflammation and oxidative stress studies

Global leukocyte counting was used in this study to evaluate the leukocyte migration to the injury sites. As shown in Fig. 4a, every tested treatment proved to be efficient in reducing the inflammation in comparison with the positive control group $(p<0.0001)$. No significant difference was observed when the NP groups were compared with the gold standard treatment group (diclofenac) and CVDL $3 \mathrm{mg} / \mathrm{kg}(p>0.05)$. There was no difference among the NP group and the NP CVDL and NP CVDL CHOL combination groups in this parameter.

GSH levels (Fig. 4b) were higher in all the treated groups than in the positive control group $(p<0.0001)$, proving that PLGA is involved in antioxidant processes. Interestingly, NP lead to higher GSH levels than the NP CVDL $(p<0.0001)$, but the addition of CHOL seems to boost the antioxidant effects of NP, since no difference was observed between NP group and the NP CVDL CHO $(0.05 \mathrm{mg} / \mathrm{kg})$ group $(p>0.05)$, whereas the levels were higher in the NP CVDL CHOL $(0.1 \mathrm{mg} / \mathrm{kg})$ and NP CVDL CHOL $(0.3 \mathrm{mg} / \mathrm{kg})(p<0.0001)$.

MDA is a secondary product of lipid peroxidation caused by oxidative stress. If there is an inflammatory process in course, MDA levels are expected to be increased, whereas GSH should remain low or decreased (Falcao et al. 2018). All tested treatments in this study were able to prevent oxidative stress and therefore MDA 


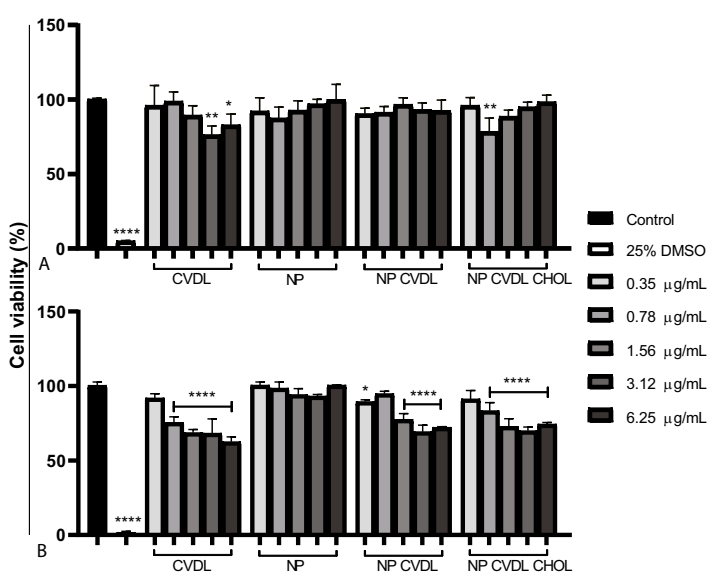

Fig. 3 Antitumor activity of nanoparticles in CT-26 cells. a, b Mean cell viability of CT-26 cells treated with CVDL, NP, NP CVDL, and NP CVDL CHOL for $24 \mathrm{~h}$ (a) and $48 \mathrm{~h}$ (b). The concentrations used were as follows: $0.35 \mu \mathrm{g} / \mathrm{mL}, 0.78 \mu \mathrm{g} / \mathrm{mL}$, $1.56 \mu \mathrm{g} / \mathrm{mL}, 3.12 \mu \mathrm{g} / \mathrm{mL}$, and $6.2 \mu \mathrm{g} / \mathrm{mL}$. All treatment groups were compared with the negative control group $(* * * * p<0.0001$, $\left.{ }^{* *} p<0.01, * p<0.05\right)$. (c, d The mean cell death statistic of the treatments of free CVDL, NP CVDL, and NP CVDL CHOL at CT-26 cells at $24 \mathrm{~h}(\mathbf{c})$ and $48 \mathrm{~h}(\mathbf{d})$ when compared with the

levels were kept low compared with the positive control (Fig. 4c) $(p<0.0001)$.

\section{Discussion}

The nanoparticles obtained by the emulsificationsolvent evaporation method showed the formation of small particles and desirable zeta potential values. Similar particle size results as in the paper about carvedilolloaded solid lipid nanoparticles for intranasal drug delivery had already been obtained in later works, where a concentration of $0.5-2.5 \%$ surfactant obtained a particle
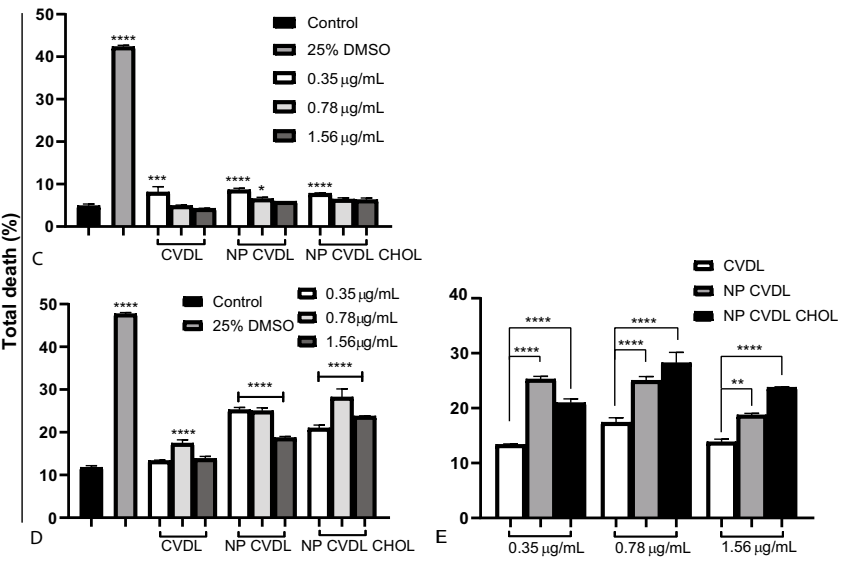

negative control $(* p<0.05, * * * p<0.001$, and $* * * * p<0.0001)$. Negative control and 25\% DMSO were used. The concentrations of CVDL, NP CVDL, and NP CVDL CHOL used were as follows: $0.35 \mu \mathrm{g} / \mathrm{mL}, 0.78 \mu \mathrm{g} / \mathrm{mL}$, and $1.56 \mu \mathrm{g} / \mathrm{mL}$. e Comparison between CVDL, NP CVDL, and NP CVDL CHOL at the concentrations $0.35 \mu \mathrm{g} / \mathrm{mL}, 0.78 \mu \mathrm{g} / \mathrm{mL}$, and $1.56 \mu \mathrm{g} / \mathrm{mL}$. The duration of treatment of CT-26 cells was $48 \mathrm{~h}(* * p<0.01$ and $* * * * p<0.0001)$

size in the range $174.35 \mathrm{~nm} \pm 1.34$ to $492.40 \mathrm{~nm} \pm 8.20$ (Qi et al. 2013). The best results were obtained with particles smaller than $300 \mathrm{~nm}$ and are ideal because they are smaller and have better adsorption (Aboud et al. 2016). The zeta potential reflects the surface charge of the particles, and the use of PLGA as the main polymer dispersed in the organic phase gave us a negative zeta potential in all results as expected (Table 1). This can be explained by considering the anionic nature of the polymer (Némethová et al. 2017). The choice of three ratios of drug:copolymer is justified because factors such as the nature and concentration of the polymer in the organic phase, the polarities of the solvents, the nature
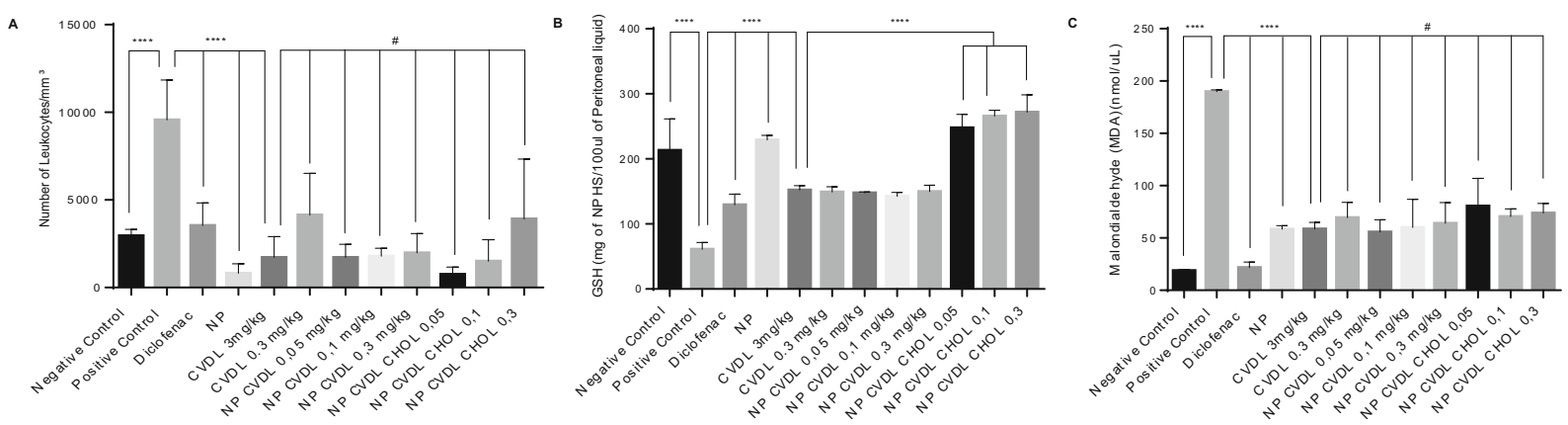

Fig. 4 a Number of leukocytes, $\mathbf{b}$ glutathione levels, and $\mathbf{c}$ malondialdehyde. ANOVA followed by Bonferroni's multiple comparisons test. $* * * * p<0.0001, \# p>0.05$ 
and ratio of the internal/external phases, and the nature and concentration of the surfactants are essential. Therefore, it was necessary to choose which of the nanoparticles among the various ratios have the best results among such factors (Baena-Aristizábal et al. 2016). The highest drug loading efficiency was observed in the formulation containing CVDL:PLGA in the weight ratio of $1: 10$. Other papers dealing with carvedilol nanoparticles have shown incorporation efficiency of up to $97 \%$, being slightly higher than ours. However, the drug amount used was greater than $1 \mathrm{mg} / \mathrm{mL}$ (Luxenhofer 2015). Thus, we had higher incorporation efficiency for the drug quantity. The drug proportion plays a critical role in determining drug loading, particle size, and particle size distribution, as well as the physical stability of the resulting products (El-Say et al. 2018). In this same reasoning, $\mathrm{CHOL}$ was incorporated as a functionalizing substance to increase the targeting for cancer cells, where there was a slight increase in particle size and a consequent decrease in encapsulation efficiency. Variations in particle size are indicative that there was an interaction between the copolymer and the drug. In addition, smaller particle size is also indicative of a larger surface area which directly reflects the encapsulation efficiency (de Oliveira et al. 2013).

The AFM images assed topography aspects such as the shape and the surface of particles. Comparisons of the images of CVDL-free nanoparticles with CVDLloaded nanoparticles and drug-loaded functionalized nanoparticles confirmed that the drug loading did not affect the formation of sub 250-nm spherical nanoparticles, corroborating the particle size measurements performed by DLS. The analysis of the AFM tip over the surface of nanoparticles records the topography, elucidating the shape and giving information about the size and surface of particles after to desiccants the samples. The more spherical and uniform the particle size, the better the release kinetics of the drug (Bazylińska et al. 2014; Doquet and Barkia 2016; M. Hoo et al. 2008).

By analyzing the infrared spectra of the nanoparticles, it is possible to observe slight shortening of peaks while adding drug and CHOL, as in the regions of $1750 \mathrm{~cm}^{-1}, 1180 \mathrm{~cm}^{-1}$, and $1050 \mathrm{~cm}^{-1}$ which respectively corresponded to monomeric peaks of the $\mathrm{C}=\mathrm{O}$, derivative of PLGA. Peaks of the $\mathrm{C}-\mathrm{N}$ aliphatic and $\mathrm{C}-\mathrm{O}$ peaks were present in the aromatic group. These changes in the spectrum are indicative of the incorporation of CVDL as well as of CHOL to the nanoparticles.
The Bhaskar model explains that the drug release rate in the particles may be limited (1-MT/M $\infty) K b=t^{0.65}+$ $b)$. This fact suggests that the drug release was controlled by diffusion dependent on the drug loading ratio from spherical particles (Gocalinska et al. 2015). This result also corroborates AFM data (Neupane et al. 2014). However, it is possible to observe that the systems show a controlled release for at least $600 \mathrm{~min}$ (although with a low percentage of release), differently from the drug that released $100 \%$ in the first minutes. Similar results were found in a work on CVDL-loaded solid lipid nanoparticles to improve the oral bioavailability, in which a maximal release of $25 \%$ of CVDL from the nanoparticles was found (Venishetty et al. 2012). Thus, our work brings even more favorable release results. In addition, the previous work does not address what kind of kinetic model causes release, which makes a difference. This capacity of nanoparticulate systems to maintain the entrapped drug into polymeric matrix in the release medium potentially improve the biological activity. This fact avoids the CVDL release before the nanoparticles arrive to the target cells, mainly considering the internalization of nanoparticles by endocytosis phenomena (Cheng et al. 2014; Lin et al. 2010; Son and Kim 2010).

Good results were obtained within the analysis in the stability study of the nanoparticles containing CVDL:PLGA at the 1:10 ratio and the nanoparticle without the drug (Fig. 2c). There were no significant variations between particle size and zeta potential values over the 7 weeks, as the zeta potential values remained positive without large variations and the particle size remained below $250 \mathrm{~nm}$. Previous studies with nanoparticles generally do not report the physical stability of proposed formulations or just consider small intervals of hours or days. These results show that there were no instability phenomena such as creaming, flocculation, sedimentation, phase separation, or coalescence (Binder et al. 2014; Grouchko et al. 2014).

The MTS viability assay is based on the ability of viable cells to transform a tetrazolium salt into a soluble formazan product through their mitochondrial activity (Malich et al. 1997). In this work, the antiproliferative activity of the samples after $24 \mathrm{~h}$ of incubation showed that the free CVDL $(3.12 \mu \mathrm{g} / \mathrm{mL}$ and $6.25 \mu \mathrm{g} / \mathrm{mL})$ and NP CVDL CHOL $(0.78 \mu \mathrm{g} / \mathrm{mL})$ were able to decrease the proliferation of tumor cells when compared with the control. Increasing the incubation time of the treatment $(48 \mathrm{~h})$ also increased the amount of non-viable cells. 
Table 1 Results of diameter, polydispersity index, zeta potential, and encapsulation efficiency in the analysis of the chosen nanoparticles

\begin{tabular}{lllll}
\hline Nanoparticles & Diameter $(\mathrm{nm}) \pm \mathrm{SD}$ & PDI $(\mathrm{nm}) \pm \mathrm{SD}$ & ZP $(\mathrm{mV}) \pm \mathrm{SD}$ & $\mathrm{EE} \pm \mathrm{SD}$ \\
\hline NP & $209.1 \pm 2.03$ & $0.137 \pm 0.01$ & $-1.03 \pm 0.2$ & - \\
NP CVDL & $227.3 \pm 9.07$ & $0.223 \pm 0.03$ & $-2.04 \pm 0.2$ & $95.06 \pm 0.4$ \\
NP CVDL CHOL & $234.7 \pm 18.7$ & $0.081 \pm 0.01$ & $-2.08 \pm 0.1$ & $37.45 \pm 1.8$ \\
\hline
\end{tabular}

$P D I$ polydispersity index), $n m$ nanometer, $S D$ standard deviation, $m V$ millivolt

Free CVDL $(0.78 \mu \mathrm{g} / \mathrm{mL}, 1.56 \mu \mathrm{g} / \mathrm{mL}, 3.12 \mu \mathrm{g} / \mathrm{mL}$, and $6.25 \mu \mathrm{g} / \mathrm{mL})$, NP CVDL $(1.56 \mu \mathrm{g} / \mathrm{mL}, 3.12 \mu \mathrm{g} / \mathrm{mL}$, and $6.25 \mu \mathrm{g} / \mathrm{mL})$, and NP CVDL CHOL $(0.78 \mu \mathrm{g} / \mathrm{mL}$, $1.56 \mu \mathrm{g} / \mathrm{mL}, 3.12 \mu \mathrm{g} / \mathrm{mL}$, and $6.25 \mu \mathrm{g} / \mathrm{mL}$ ) did not present statistical difference between them in viability after $48 \mathrm{~h}$. On the other hand, NP did not present antiproliferative activity at 24 and $48 \mathrm{~h}$, confirming the biocompatible PLGA characteristic, making it a safe candidate as a drug delivery system (Fig. 3a, b) (Choi et al. 2019; El-Hammadi et al. 2017; Ramalho et al. 2018).

All compounds induced cell death by flow cytometry at both treatment times, although the amount of total cell death was more significant after $48 \mathrm{~h}$. This result confirms the data observed in the MTS, corroborating that the release of the drug by the nanoparticles occurs later (Liu et al. 2015). Low-dose CVDL $(0.35 \mu \mathrm{g} / \mathrm{mL})$ does not induce cell death when compared with control at $48 \mathrm{~h}$, whereas NP CVDL and NP CVDL CHOL induce cell death; this outcome is an important finding which can prevent side effects in future use as an antitumor agent. It may be possible to use less amount of CVDL when encapsulated in nanoparticles and thus reduce likely side effects when higher doses of the drug are used (Waghela et al. 2015). There is a difference between the amount of cell death when comparing the free CVDL and the nanoparticle systems at the same concentration (Fig. 3e). This result demonstrates the increased efficiency of the antitumor activity of CVDL when present in a functionalized system (Wang et al. 2018). NP CVDL CHOL showed greater efficiency in inducing cell death than NP CVDL at doses $0.78 \mu \mathrm{g} / \mathrm{mL}$ and $1.56 \mu \mathrm{g} / \mathrm{mL}$ at $48 \mathrm{~h}$, and this data corroborates other works which showed the promising cholesteroltargeting characteristic (Kong et al. 2019; Lee et al. 2016; Li et al. 2018; Mazumdar et al. 2018).

Many studies have proven that PLGA is an efficient delivery system of different active components, mainly if functionalized with cholesterol (Lee et al. 2016; Mazumdar et al. 2018). In this study, the treatment with NP CVDL CHOL $(0.05 \mathrm{mg} / \mathrm{kg}$ and $0.1 \mathrm{mg} / \mathrm{kg})$ is more efficient in decreasing leukocyte migration as well as increasing the GSH levels at all tested doses $(0.05 \mathrm{mg} / \mathrm{kg}, 0.1$, and $0.3 \mathrm{mg} / \mathrm{kg})$ than free CVDL and NP CVDL. As shown in Fig. 4, NP CVDL or NP CVDL CHOL $(0.05 \mathrm{mg} / \mathrm{kg})$ show similar activity regarding leukocyte levels, MDA and GSH when these data are compared with free CVDL at a concentration of $3 \mathrm{mg} / \mathrm{kg}$. Thus, using functionalized nanoparticles with CHOL decreased the amount of CVDL without compromising its anti-inflammatory and antioxidant effects. These results suggest that PLGA nanoparticles functionalized with cholesterol can enhance the cellular uptake of pharmacological compounds, preventing lipid peroxidation and leukocyte migration in inflammatory processes (Alqahtani et al. 2015; Astete et al. 2011; Nallamuthu et al. 2013; Pereira et al. 2018).

Table 2 Fitting parameters of different kinetic models applied for the in vitro CVDL release from PLGA nanoparticles

\begin{tabular}{lllll}
\hline Formulations & \multicolumn{1}{l}{ Kinetic models } & & \\
\cline { 2 - 5 } a & First order & Bhaskar & Freundlich & Parabolic Diffusion \\
\hline NP CVDL & & & & \\
NP CVDL CHOL & $0.0059 \mathrm{~h}^{-1}(0.90 \pm 0.03)$ & $0.52 \mathrm{~h}^{0.65}(0.96 \pm 0.02)$ & $50.43 \mathrm{~h}(0.93 \pm 0.03)$ & $0.30 \mathrm{~h}^{-0.5}(0.47 \pm 0.03)$ \\
\hline
\end{tabular}




\section{Conclusion}

In this study, we successfully developed carvedilolloaded polymeric nanoparticles and improved cell uptake of carvedilol as chemotherapy agent. Nanoparticles have shown suitable structure features as small and stable particles able to induce both the high encapsulation efficiency and the slow drug release profile for CVDL. The data presented indicates that the NP CVDL CHOL can be used as a drug carrier with promising antitumor, antioxidant, and anti-inflammatory activity.

Authors' contributions Conceptualization: Raimundo F. de Araújo Júnior, Arnóbio A. da Silva-Júnior, and Aurigena A. de Araújo; Formal Analysis: Ana Luiza C. de S. L. Oliveira, Alaine M. dos Santos-Silva, and Vinícius B. Garcia; Writing-original draft preparation: Ana Luiza C. de S. L. Oliveira, Alaine M. dos Santos-Silva, and Vinícius B. Garcia; Writing-review \& editing: Ana Luiza C. de S. L. Oliveira, Raimundo F. de Araújo Júnior, and Arnóbio A. da Silva-Júnior; Supervision: Raimundo F. de Araújo Júnior, Lioe-Fee de Geus-Oei, and Luis J. Cruz; Project administration: Alan B. Chan; Funding acquisition: Alan B. Chan.

Funding information This work received financial support from the Coordenação de Aperfeiçoamento de Pessoal de Nivel Superior (CAPES) [grant numbers 88881.133518/2016-01, 88881.119850/2016-01]. The authors received financial support from the Brazilian National Council for Scientific and Technological Development $(C N P q)$ [grant numbers: 481767/2012-6, 308382/2017-0] and the LUMC fellowship grant, project EU Program H2020-MSCA-RISE-2017-CANCER [grant number 777682].Data availabilityThe datasets generated during and/or analyzed during the current study are available from the corresponding author on reasonable request.

\section{Compliance with ethical standards}

Conflict of interest The authors declare that they have no conflict of interest.

\footnotetext{
Open Access This article is licensed under a Creative Commons Attribution 4.0 International License, which permits use, sharing, adaptation, distribution and reproduction in any medium or format, as long as you give appropriate credit to the original author(s) and the source, provide a link to the Creative Commons licence, and indicate if changes were made. The images or other third party material in this article are included in the article's Creative Commons licence, unless indicated otherwise in a credit line to the material. If material is not included in the article's Creative Commons licence and your intended use is not permitted by statutory regulation or exceeds the permitted use, you will need to obtain permission directly from the copyright holder. To view a copy of this licence, visit http://creativecommons.org/licenses/by/4.0/.
}

\section{References}

Aboud HM, El Komy MH, Ali AA, El Menshawe SF, Abd Elbary A (2016) Development, optimization, and evaluation of carvedilol-loaded solid lipid nanoparticles for intranasal drug delivery AAPS. Pharm Sci Tech 17:1353-1365. https://doi. org/10.1208/s12249-015-0440-8

Alqahtani S et al (2015) Cellular uptake, antioxidant and antiproliferative activity of entrapped $\alpha$-tocopherol and $\gamma$ tocotrienol in poly (lactic-co-glycolic) acid (PLGA) and chitosan covered PLGA nanoparticles (PLGA-Chi). J Colloid Interface Sci 445:243-251. https://doi.org/10.1016/j. jcis.2014.12.083

Anderson ME (1985) Determination of glutathione and glutathione disulfide in biological samples. Methods Enzymol 113: $548-555$

Araújo Júnior RF, Garcia VB, RFdC L, GAdC B, EdC M, PMM G, de Araújo AA (2016) Carvedilol improves inflammatory response, oxidative stress and fibrosis in the alcohol-induced liver injury in rats by regulating Kuppfer cells and hepatic stellate cells. PLoS One 11:e0148868. https://doi. org/10.1371/journal.pone.0148868

Areti A, Komirishetty P, Kumar A (2017) Carvedilol prevents functional deficits in peripheral nerve mitochondria of rats with oxaliplatin-evoked painful peripheral neuropathy. Toxicol Appl Pharmacol 322:97-103. https://doi. org/10.1016/j.taap.2017.03.009

Astete CE, Dolliver D, Whaley M, Khachatryan L, Sabliov CM (2011) Antioxidant poly(lactic-co-glycolic) acid nanoparticles made with alpha-tocopherol-ascorbic acid surfactant. ACS Nano 5:9313-9325. https://doi.org/10.1021/nn102845t

Baena-Aristizábal CM, Fessi H, Elaissari A, Mora-Huertas CE (2016) Biodegradable microparticles preparation by double emulsification - solvent extraction method: a systematic study. Colloids Surf A Physicochem Eng Asp 492:213229. https://doi.org/10.1016/j.colsurfa.2015.11.067

Bahrami B, Hojjat-Farsangi M, Mohammadi H, Anvari E, Ghalamfarsa G, Yousefi M, Jadidi-Niaragh F (2017) Nanoparticles and targeted drug delivery in cancer therapy. Immunol Lett 190:64-83. https://doi.org/10.1016/j. imlet.2017.07.015

Balaha M, Kandeel S, Barakat W (2016) Carvedilol suppresses circulating and hepatic IL-6 responsible for hepatocarcinogenesis of chronically damaged liver in rats. Toxicol Appl Pharmacol 311. https://doi.org/10.1016/j. taap.2016.10.012

Bazylińska U, Lewińska A, Lamch Ł, Wilk KA (2014) Polymeric nanocapsules and nanospheres for encapsulation and long sustained release of hydrophobic cyanine-type photosensitizer. Colloids Surf A Physicochem Eng Asp 442:42-49. https://doi.org/10.1016/j.colsurfa.2013.02.023

Binder K, Virnau P, Statt A (2014) Perspective: the Asakura Oosawa model: a colloid prototype for bulk and interfacial phase behavior. J Chem Phys 141:140901. https://doi. org/10.1063/1.4896943

Cheng Y, Morshed R, Auffinger B, Tobias AL, Lesniak MS (2014) Multifunctional nanoparticles for brain tumor diagnosis and therapy Adv Drug Deliv Rev 0:42-57 doi:https://doi. org/10.1016/j.addr.2013.09.006, 66 
Choi DG, Venkatesan J, Shim MS (2019) Selective anticancer therapy using pro-oxidant drug-loaded chitosan-fucoidan nanoparticles. Int J Mol Sci 20:20. https://doi.org/10.3390 /ijms20133220

Coussens LM, Werb Z (2002) Inflammation and cancer. Nature 420:860-867. https://doi.org/10.1038/nature01322

Danhier F, Ansorena E, Silva JM, Coco R, Le Breton A, Preat V (2012) PLGA-based nanoparticles: an overview of biomedical applications. J Control Release 161:505-522. https://doi. org/10.1016/j.jconrel.2012.01.043

De Araujo RF Jr et al (2018) Apoptosis in human liver carcinoma caused by gold nanoparticles in combination with carvedilol is mediated via modulation of MAPK/Akt/mTOR pathway and EGFR/FAAD proteins. Int J Oncol 52:189-200. https://doi.org/10.3892/ijo.2017.4179

de Oliveira AM, Jäger E, Jäger A, Stepánek P, Giacomelli FC (2013) Physicochemical aspects behind the size of biodegradable polymeric nanoparticles: a step forward. Colloids Surf A Physicochem Eng Asp 436:1092-1102. https://doi. org/10.1016/j.colsurfa.2013.08.056

Doquet V, Barkia B (2016) Combined AFM, SEM and crystal plasticity analysis of grain boundary sliding in titanium at room temperature. Mech Mater:103-127. https://doi. org/10.1016/j.mechmat.2016.09.001

dos Santos Silva AM et al (2019) Hydrophilic and hydrophobic polymeric benznidazole-loaded nanoparticles: physicochemical properties and in vitro antitumor efficacy. Journal of Drug Delivery Science and Technology 51:700-707. https://doi.org/10.1016/j.jddst.2019.04.005

dos Santos-Silva AM, de Caland LB, de ALC SLO, de AraújoJúnior RF, Fernandes-Pedrosa MF, Cornélio AM, da SilvaJúnior AA (2017) Designing structural features of novel benznidazole-loaded cationic nanoparticles for inducing slow drug release and improvement of biological efficacy. Mater Sci Eng C 78:978-987. https://doi.org/10.1016/j. msec.2017.04.053

Dos Santos-Silva AM et al (2019) Self-assembled benznidazoleloaded cationic nanoparticles containing cholesterol/sialic acid: physicochemical properties, in vitro drug release and in vitro anticancer efficacy. Int J Mol Sci 20. https://doi. org/10.3390/ijms20092350

El-Hammadi MM, Delgado ÁV, Melguizo C, Prados JC, Arias JL (2017) Folic acid-decorated and PEGylated PLGA nanoparticles for improving the antitumour activity of 5-fluorouracil. Int J Pharm 516:61-70. https://doi.org/10.1016/j. ijpharm.2016.11.012

Elinav E, Nowarski R, Thaiss CA, Hu B, Jin C, Flavell RA (2013) Inflammation-induced cancer: crosstalk between tumours, immune cells and microorganisms. Nat Rev Cancer 13: 759-771. https://doi.org/10.1038/nrc3611

El-Say K, Hosny KM, Alkhalidi H (2018) Quality by design approach to screen the formulation and process variables influencing the characteristics of carvedilol solid lipid nanoparticles. J Drug Deliv Sci Technol:45-168. https://doi. org/10.1016/j.jddst.2018.03.010

Esterbauer H, Cheeseman KH (1990) Determination of aldehydic lipid peroxidation products: malonaldehyde and 4hydroxynonenal. Methods Enzymol 186:407-421

Falcao TR et al (2018) Crude extract and fractions from Eugenia uniflora Linn leaves showed anti-inflammatory, antioxidant, and antibacterial activities. BMC Complement Altern Med 18:84. https://doi.org/10.1186/s12906-018-2144-6

Félix L et al (2017) Carvedilol exacerbate gentamicin-induced kidney mitochondrial alterations in adult rat. Exp Toxicol Pathol 69:83-92. https://doi.org/10.1016/j.etp.2016.11.006

Ghuman S et al (2017) Serum inflammatory markers and colorectal cancer risk and survival. Br J Cancer 116:1358-1365. https://doi.org/10.1038/bjc.2017.96

Gocalinska A, Manganaro M, Dimastrodonato V, Pelucchi E (2015) Evaluation of defect density by top-view large scale AFM on metamorphic structures grown by MOVPEvol 349. doi:https://doi.org/10.1016/j.apsusc.2015.05.070

Goyal R, Macri LK, Kaplan HM, Kohn J (2016) Nanoparticles and nanofibers for topical drug delivery. J Control Release 240:77-92. https://doi.org/10.1016/j.jconrel.2015.10.049

Grouchko M, Roitman P, Zhu X, Popov I, Kamyshny A, Su H, Magdassi S (2014) Merging of metal nanoparticles driven by selective wettability of silver nanostructures. Nat Commun 5: 2994. https://doi.org/10.1038/ncomms3994

Hans ML, Lowman A (2002) Biodegradable nanoparticles for drug delivery and targeting. Curr Opinion Solid State Mater Sci 6:319. https://doi.org/10.1016/S1359-0286(02)00117-1

Hoo CM, Starostin N, West P, Mecartney M (2008) A comparison of atomic force microscopy (AFM) and dynamic light scattering (DLS) methods to characterize nanoparticle size distribution. J Nanopart Res 10. https://doi.org/10.1007/s11051008-9435-7

Kapadia CH, Perry JL, Tian S, Luft JC, DeSimone JM (2015) Nanoparticulate immunotherapy for cancer. J Control Release 219:167-180. https://doi.org/10.1016/j. jconrel.2015.09.062

Kong ZL, Kuo HP, Johnson A, Wu LC, Chang KLB (2019) Curcumin-loaded mesoporous silica nanoparticles markedly enhanced cytotoxicity in hepatocellular carcinoma cells. Int J Mol Sci:20. https://doi.org/10.3390/ijms20122918

Lee BK, Yun YH, Park K (2015) Smart nanoparticles for drug delivery: boundaries and opportunities. Chem Eng Sci 125: 158-164. https://doi.org/10.1016/j.ces.2014.06.042

Lee J-J, Lee SY, Park J-H, Kim D-D, Cho H-J (2016) Cholesterolmodified poly(lactide-co-glycolide) nanoparticles for tumortargeted drug delivery. Int J Pharm 509:483-491. https://doi. org/10.1016/j.ijpharm.2016.06.008

Li H, Tong Y, Bai L, Ye L, Zhong L, Duan X, Zhu Y (2018) Lactoferrin functionalized PEG-PLGA nanoparticles of shikonin for brain targeting therapy of glioma. Int $\mathrm{J}$ Biol Macromol 107:204-211. https://doi.org/10.1016/j. ijbiomac.2017.08.155

Lin J, Zhang H, Chen Z, Zheng Y (2010) Penetration of lipid membranes by gold nanoparticles: insights into cellular uptake, cytotoxicity, and their relationship. ACS Nano 4:54215429. https://doi.org/10.1021/nn1010792

Liu P et al (2015) Development of alendronate-conjugated poly (lactic-co-glycolic acid)-dextran nanoparticles for active targeting of cisplatin in osteosarcoma. Sci Rep 5:1738717387. https://doi.org/10.1038/srep17387

Luxenhofer R (2015) Polymers and nanomedicine: considerations on variability and reproducibility when combining complex systems. Nanomedicine (Lond) 10:3109-3119. https://doi. org/10.2217/nnm.15.139

Malich G, Markovic B, Winder C (1997) The sensitivity and specificity of the MTS tetrazolium assay for detecting the 
in vitro cytotoxicity of 20 chemicals using human cell lines. Toxicology 124:179-192. https://doi.org/10.1016/S0300483X(97)00151-0

Masloub SM, Elmalahy MH, Sabry D, Mohamed WS, Ahmed SH (2016) Comparative evaluation of PLGA nanoparticle delivery system for 5-fluorouracil and curcumin on squamous cell carcinoma. Arch Oral Biol 64:1-10. https://doi.org/10.1016 /j.archoralbio.2015.12.003

Mazumdar S, Italiya KS, Sharma S, Chitkara D, Mittal A (2018) Effective cellular internalization, cell cycle arrest and improved pharmacokinetics of tamoxifen by cholesterol based lipopolymeric nanoparticles. Int J Pharm 543:96-106. https://doi.org/10.1016/j.ijpharm.2018.03.022

Milling L, Zhang Y, Irvine DJ (2017) Delivering safer immunotherapies for cancer. Adv Drug Deliv Rev 114:79-101. https://doi.org/10.1016/j.addr.2017.05.011

Nallamuthu I, Parthasarathi A, Khanum F (2013) Thymoquinoneloaded PLGA nanoparticles: antioxidant and anti-microbial properties vol 2. doi:https://doi.org/10.3329/icpj.v2 i12.17017

Némethová V et al (2017) Intracellular uptake of magnetite nanoparticles: a focus on physico-chemical characterization and interpretation of in vitro data. Mater Sci Eng C 70:161-168. https://doi.org/10.1016/j.msec.2016.08.064

Neupane YR, Srivastava M, Ahmad N, Kumar N, Bhatnagar A, Kohli K (2014) Lipid based nanocarrier system for the potential oral delivery of decitabine: formulation design, characterization, ex vivo, and in vivo assessment. Int $\mathrm{J}$ Pharm 477:601-612. https://doi.org/10.1016/j.jpharm.2014.11.001

Ng SF, Rouse JJ, Sanderson FD, Meidan V, Eccleston GM (2010) Validation of a static Franz diffusion cell system for in vitro permeation studies. AAPS PharmSciTech 11:1432-1441. https://doi.org/10.1208/s12249-010-9522-9

Pereira MC et al (2018) Effect of nanoencapsulation using PLGA on antioxidant and antimicrobial activities of guabiroba fruit phenolic extract. Food Chem 240:396-404. https://doi. org/10.1016/j.foodchem.2017.07.144

Pooja D, Tunki L, Kulhari H, Reddy BB, Sistla R (2016) Optimization of solid lipid nanoparticles prepared by a single emulsification-solvent evaporation method. Data Brief 6:1519. https://doi.org/10.1016/j.dib.2015.11.038

Qi F, Zhang X, Li S (2013) A novel method to get methotrexatum/ layered double hydroxides intercalation compounds and their release properties. J Phys Chem Solids 74:1101-1108. https://doi.org/10.1016/j.jpcs.2013.03.005

Ramalho MJ, Sevin E, Gosselet F, Lima J, Coelho MAN, Loureiro JA, Pereira MC (2018) Receptor-mediated PLGA nanoparticles for glioblastoma multiforme treatment. Int J Pharm 545: 84-92. https://doi.org/10.1016/j.ijpharm.2018.04.062

Ramezanpour M, Leung SSW, Delgado-Magnero KH, Bashe BYM, Thewalt J, Tieleman DP (2016) Computational and experimental approaches for investigating nanoparticle- based drug delivery systems. Biochim Biophys Acta Biomembr 1858:1688-1709. https://doi.org/10.1016/j. bbamem.2016.02.028

Ribeiro RA, Flores CA, Cunha FQ, Ferreira SH (1991) IL-8 causes in vivo neutrophil migration by a cell-dependent mechanism. Immunology 73:472-477

Son S, Kim WJ (2010) Biodegradable nanoparticles modified by branched polyethylenimine for plasmid DNA delivery. Biomaterials 31:133-143. https://doi.org/10.1016/j. biomaterials.2009.09.024

Taniguchi K, Karin M (2018) NF-kappaB, inflammation, immunity and cancer: coming of age. Nat Rev Immunol 18:309324. https://doi.org/10.1038/nri.2017.142

Varan G, Öncül S, Ercan A, Benito JM, Ortiz Mellet C, Bilensoy E (2016) Cholesterol-targeted anticancer and apoptotic effects of anionic and polycationic amphiphilic cyclodextrin nanoparticles. J Pharm Sci 105:3172-3182. https://doi. org/10.1016/j.xphs.2016.06.021

Venishetty VK, Chede R, Komuravelli R, Adepu L, Sistla R, Diwan PV (2012) Design and evaluation of polymer coated carvedilol loaded solid lipid nanoparticles to improve the oral bioavailability: a novel strategy to avoid intraduodenal administration. Colloids Surf B: Biointerfaces 95:1-9. https://doi.org/10.1016/j.colsurfb.2012.01.001

Waghela BN, Sharma A, Dhumale S, Pandey SM, Pathak C (2015) Curcumin conjugated with PLGA potentiates sustainability, anti-proliferative activity and apoptosis in human colon carcinoma cells. PLoS One 10:e117526-e0117526. https://doi.org/10.1371/journal.pone.0117526

Wang W, Chen T, Xu H, Ren B, Cheng X, Qi R, Liu H, Wang Y, Yan L, Chen S, Yang Q, Chen C (2018) Curcumin-loaded solid lipid nanoparticles enhanced anticancer efficiency in breast cancer. Molecules:23. https://doi.org/10.3390 /molecules23071578

West NR, McCuaig S, Franchini F, Powrie F (2015) Emerging cytokine networks in colorectal cancer. Nat Rev Immunol 15: 615-629. https://doi.org/10.1038/nri3896

Yao K, Zhang WW, Yao L, Yang S, Nie W, Huang F (2016) Carvedilol promotes mitochondrial biogenesis by regulating the PGC-1/TFAM pathway in human umbilical vein endothelial cells (HUVECs). Biochem Biophys Res Commun 470:961-966. https://doi.org/10.1016/j.bbrc.2016.01.089

Zhu M, Shi J, He Q, Zhang L, Chen F, Chen Y (2012) An emulsification-solvent evaporation route to mesoporous bioactive glass microspheres for bisphosphonate drug delivery. $\mathrm{J}$ Mater Sci 47:2256. https://doi.org/10.1007/s10853-0116037-z

Publisher's note Springer Nature remains neutral with regard to jurisdictional claims in published maps and institutional affiliations. 